\section{Elevated Temperatures During Simulated Marketing Reduce Field Performance of Packaged Rose Bushes}

\author{
C. Klobucher Welch and A.C. Cameron \\ Department of Horticulture, Michigan State University, East Lansing, \\ MI 48824
}

Additional index words. Rosa, postharvest storage, wax

\begin{abstract}
Bare-root garden rose' (Rosa) cultivars Show Biz, Tropicana, Hotel Hershey, and Femme were packaged according to standard nursery practice with roots surrounded by peat. After 4 weeks of simulated marketing at $23 \mathrm{C}$, the plants produced half as many breaks, half as many flowers, half as much seasonal cane growth, and had reduced survival when field-grown for 1 year, compared to plants held 4 weeks at 3C. Waxing of canes before treatment reduced water loss during simulated marketing and increased lateral breaks, total season cane growth, and, in some cases, flower production. Waxing also induced faster development of new lateral breaks, but, at $23 \mathrm{C}$, induction occurred before planting and these breaks survived poorly in the field. The antitranspirant Cloud Cover did not affect moisture loss or improve field performance.
\end{abstract}

Several million garden rose bushes are sold annually throughout the United States. Most are field-grown in California, Arizona, and Texas and harvested bare-root in late fall. Bare-root roses are usually placed unboxed in open racks and- held in refrigerated storage. Moisture is provided by periodic misting of the plants. The optimum temperature for long-term storage has been found to be in the range of -1 to $+2 \mathrm{C}$ (Janne and Chadwick, 195 1; Mahlstede and Fletcher, 1960; Yerkes and Gardner, 1934). In the northern United States, it is not at all uncommon for roses to be stored through April, although extended storage duration has been shown to reduce subsequent field performance (Janne and Chadwick, 1951). Before marketing through retail stores $m$ the spring, rose plants are removed from storage, trimmed, and the root systems are covered with moistened peatmoss and wrapped in plastic tied near the crown.

Packaged roses seldom are refrigerated during marketing and thus are commonly exposed to elevated temperatures for days to several weeks until sold and planted. To our knowledge, there have been no reports on the effects of elevated temperatures on subsequent field performance of such packaged rose bushes, although rose producers assume at least a 4-week shelf life even when roses are displayed at room temperature.

Waxing has been found to retard water loss from the canes and improve subsequent field performance, as measured by cane and

\footnotetext{
Received for publication 10 Nov. 1986. We acknowledge the Michigan Agr. Expt. Sta. for their support of this research. We thank Jane Waldron for her aid in preparation of the manuscript. Reference to commercial products does not imply endorsement by the authors. The cost of publishing this paper was defrayed in part by the payment of page charges. Under postal regulations, this paper therefore must be hereby marked advertisement solely to indicate this fact.
}

flower production (Toy and Mahlstede, 1959; Cameron and Workman, unpublished data), although the effect was less for late-season roses (Toy, 1959). However, waxed canes are unsightly and detract from the visual quality of the packaged roses, and waxing has, at times, been held responsible for unspecified losses in quality. Several antitranspirants currently on the market supposedly retard the rate of moisture loss from leaves. If effective, such antitranspirants could be used in place of wax, since many would not appreciably alter the appearance of the canes.

The study reported here determined the effect of elevated temperature commonly encountered during retail marketing on subsequent field performance of packaged rose bushes and examined the relation to water loss.

Dormant 'Femme', 'Tropicana', 'Hotel Hershey', and 'Show Biz' rose plants were removed from commercial refrigerated storage (1 to 3C) on 4 May 1985. All plants were disbudded as needed, top-pruned to 41 $\mathrm{cm}$, and root-pruned to $30 \mathrm{~cm}$. Canes above the crown were dipped into hot wax (80C) or an antitranspirant (Cloud Cover, diluted 1:10; Easy Gardener, Waco, Texas) or left untreated. After treatment, the roots were wrapped in moistened peatmoss and plastic wrap according to common nursery practice.

Packaged roses were held for 4 weeks of simulated marketing at either 3 or $23 \mathrm{C}$ and low-light conditions. The relative humidity ranged from $40 \%$ to $50 \%$ at $3 \mathrm{C}$ and from $20 \%$ to $30 \%$ at $23 \mathrm{C}$.

Each week of the simulated marketing period, three canes from each treatment were collected for moisture analysis. Moisture content was determined by comparison of weights before and after drying at $70 \mathrm{C}$ for 5 days.

All roses were planted at the Horticultural Research Center, East Lansing, Mich., on 1 June 1985 . The few days following planting were particularly windy and dry. Plants were irrigated, lightly cultivated to control weeds, and sprayed for disease control as needed throughout the growing season.

The number of lateral budbreaks was counted weekly for the first 6 weeks following planting. The field survival of buds initiated during simulated marketing was also monitored.

Flower production commenced in some treatments during the 4th week after planting and was monitored two to three times weekly until flowering ceased during the 2 nd week of November after the first killing frost. Flowering stems were cut back to the first strong five-leaflet node when the sepals had completely reflexed and the petals were opening.

Percent survival of plants for each treatment group during the first season was measured on 7 Nov. 1985. After onset of dormancy, the number of lateral canes and length per cane were recorded for each plant. Plants were mounded heavily with straw in December and were rated for winter survival on the basis of the presence of new lateral breaks the following spring (11 June 1986).

The data were analyzed as a three-way analysis of variance of a completely randomized design with six replicate plants per treatment.

Statistically, all four rose cultivars responded similarly with respect to cane moisture content, which showed only a slight decline during 4 weeks of simulated marketing at $3 \mathrm{C}$. There were no significant differences in moisture content between plants dipped in wax, the antitranspirant, or not treated (Fig. 1).

There was a marked decline in cane moisture content, which was reduced, in part, by waxing, during 4 weeks of simulated marketing at 23C (Fig. 1). Cloud Cover provided only slight, if any, protection against moisture loss at 23C. Averaged over 4 weeks, canes treated with Cloud Cover averaged 33\% moisture, while untreated canes averaged $28 \%$ moisture and waxed canes $43 \% \quad\left(\mathrm{LSD}_{0.05}=\right.$ 4.0).

Very few new budbreaks were noted on the rose bushes at planting time, except on those that had been waxed and held at $23 \mathrm{C}$ (Fig. 2). On these plants, there was an average of five budbreaks per plant for each of the four cultivars, of which only about one half survived the first week in the field. This decrease in the number of plants accounts for the drop in breaks shown between weeks $\mathrm{O}$ and 1 for waxed roses from 23C simulated marketing (Fig. 2). Yerkes and Gardner (1934) have noted that budbreak increases with the moisture content of packing material during bare-root storage at 7 to $9 \mathrm{C}$. It is probable that the higher moisture content of the waxed plants combined with the conditions at 23C was responsible for promotion of bud growth before planting. Of the few breaks noted on plants in other treatment combinations, very few survived the first week in the field (data not shown).

Waxed roses of all four cultivars initiated rapid budbreak in the field following simu- 


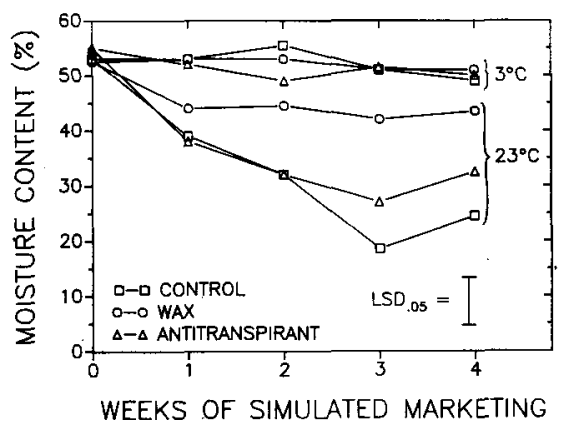

Fig. 1. The percent moisture content of packaged rose canes during simulated marketing at 3 and $23 \mathrm{C}$. At time 0 , canes were dipped into wax, antitranspirant, or left untreated. All cultivars responded similarly based on statistical analysis.
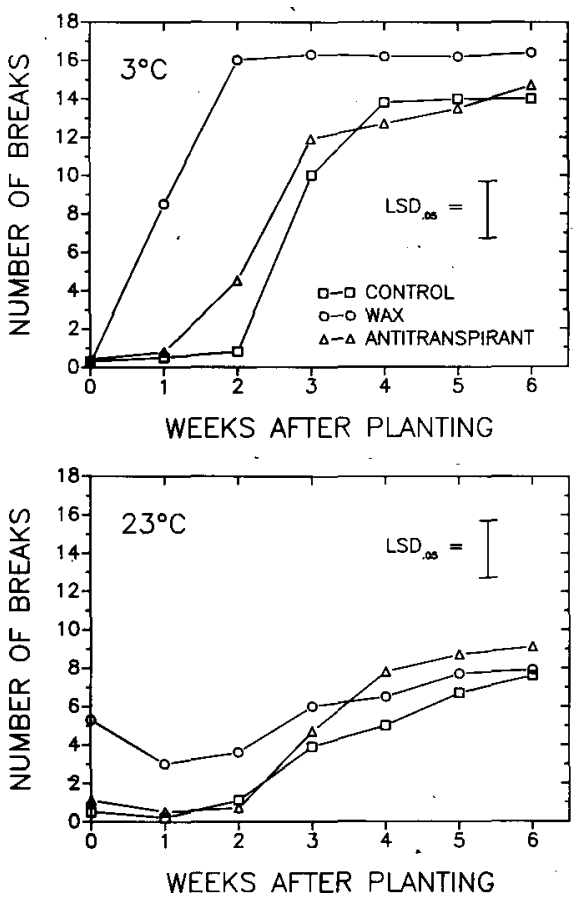

Fig. 2. Number of viable breaks on rose plants for the first 6 weeks following planting as influenced by 4 weeks of simulated marketing at 3 or $23 \mathrm{C}$ and by moisture barrier treatment to canes. All cultivars responded similarly based on statistical analysis.

lated marketing at $3 \mathrm{C}$ (Fig. 2). After the 2nd week, there was no further initiation of new breaks. In contrast, Cloud Cover-treated and untreated roses held at $3 \mathrm{C}$ did not initiate significant budbreak until the 2nd and 3rd weeks in the field, respectively (Fig. 2). Although by the 4 th week, the differences be-

Table 2. Mean total number of canes, length per cane, and total cane length produced during the first growing season by four cultivars of roses. Initially, the canes of packaged roses were treated with moisture barrier and the plants were held 4 weeks at either 3 or $23 \mathrm{C}$ of simulated marketing conditions before planting. No interactions were significant at the $5 \%$ level, so only main effects are presented.

\begin{tabular}{lccc}
\hline & \multicolumn{2}{c}{ Cane $^{\mathbf{z}}$} \\
\cline { 2 - 4 } Variable & No. & $\begin{array}{c}\text { Length each } \\
(\mathrm{cm})\end{array}$ & $\begin{array}{c}\text { Total length/plant } \\
(\mathrm{cm})\end{array}$ \\
\hline Holding temp $\left({ }^{\circ} \mathrm{C}\right)$ & & & \\
3 & 12.3 & 19.1 & 235 \\
23 & 6.4 & 18.6 & 120 \\
& $(1.4)$ & $(\mathrm{NS})$ & $(28)$ \\
Moisture barrier & 10.7 & 19.9 & 213 \\
Wax & 9.3 & 17.5 & 163 \\
Antitranspirant & 8.1 & 19.1 & 155 \\
None & $(1.7)$ & $(\mathrm{NS})$ & $(34)$ \\
& & & 121 \\
Cultivar & 13.8 & 8.8 & 239 \\
Show Biz & 8.8 & 27.2 & 179 \\
Tropicana & 8.8 & 20.3 & 118 \\
Hotel Hershey & 6.2 & 19.1 & $(39)$ \\
Femme & $(4.1)$ & $(2.0)$ & - \\
\end{tabular}

${ }^{2}$ Numbers in parentheses are $\mathrm{LSD}_{0.05}$ for mean comparison; NS = nonsignificant at $P=0.05$.

tween moisture barrier treatments were less marked and not usually detectable in the field.

Four weeks of simulated marketing at 23C retarded the rate of budbreak and reduced the total number of breaks after 6 weeks by about one half, compared to roses held at $3 \mathrm{C}$ (Fig. 2). Neither of the two moisture barriers markedly improved performance in the field over the controls. It should be noted that waxed plants did initiate earlier breaks, but these occurred during the simulated marketing period at $23 \mathrm{C}$, as discussed previously, and survived poorly in the field.

The temperature of the simulated marketing period greatly affected total flower production by the four cultivars (Table 1). With few exceptions, total flower production following $3 \mathrm{C}$ simulated marketing was two to three times that following $23 \mathrm{C}$ simulated marketing for all combinations of cultivar and moisture barrier treatment. Overall, roses held initially at $3 \mathrm{C}$ produced 29 flowers per plant, compared to 15 flowers per plant following holding at $23 \mathrm{C}$.

'Show Biz', a floribunda-type rose, produced the most flowers of the four cultivars tested and had markedly greater flower production following waxing and storage at $3 \mathrm{C}$ (Table 1). This increase was due primarily to a second burst in flower production by waxed plants between weeks 13 and 17, a burst that was largely absent in other treatment combinations (data not shown).

Waxing consistently increased total flower production by the cultivars Tropicana, Femme, and Hotel Hershey, compared to nontreated controls, when held at $3 \mathrm{C}$ (Table

Table 1. Total number of flowers produced during the first growing season by four cultivars of roses as influenced by moisture barrier and temperature during 4 weeks of simulated marketing of packaged plants before planting. LSD $_{0.05}=6$ for the three-way interaction based on analysis of variance.

\begin{tabular}{|c|c|c|c|c|c|c|c|c|}
\hline \multirow{4}{*}{$\begin{array}{l}\text { Moisture } \\
\text { barrier }\end{array}$} & \multicolumn{8}{|c|}{ Cultivar } \\
\hline & \multicolumn{2}{|c|}{ Show Biz } & \multicolumn{2}{|c|}{ Tropicana } & \multicolumn{2}{|c|}{ Hotel Hershey } & \multicolumn{2}{|c|}{ Femme } \\
\hline & \multicolumn{8}{|c|}{ Temp $\left({ }^{\circ} \mathrm{C}\right)$} \\
\hline & 3 & 23 & 3 & 23 & 3 & 23 & 3 & 23 \\
\hline$\overline{\text { Wax }}$ & 82 & 35 & 21 & 11 & 34 & 16 & 17 & 6 \\
\hline Antitranspirant & 38 & 27 & 19 & 10 & 31 & 10 & 17 & 8 \\
\hline None & 34 & 18 & 14 & 10 & 28 & 20 & 14 & 5 \\
\hline
\end{tabular}

1). However, this increase was quite small on a relative basis, accounting for an increase of only five flowers per plant the entire season. Plants treated with Cloud Cover and held at $3 \mathrm{C}$ were generally intermediate in terms of rose production (Table 1).

Neither of the two moisture barriers consistently improved flower production by 'Tropicana', 'Hotel Hershey', or 'Femme' held 4 weeks at 23C (Table 1). However, both waxing and Cloud Cover treatments significantly increased the number of flowers produced by 'Show Biz' plants held at 23C.

By the end of the season, rose bushes held 4 weeks at $23 \mathrm{C}$ before planting had produced only about one half the total amount of cane growth compared to plants held initially at 3C (Table 2), which was related to a decrease in the number of breaks, since there was no significant difference in length per cane (Table 2).

Waxing of canes before simulated marketing had a significant, but less dramatic, effect on cane length (Table 2). Waxed roses produced $37 \%$ more cane length than did the controls. Cloud Cover did not significantly increase cane production over controls. The effect of moisture barrier on total cane production was due primarily to increased number of canes and not to length per cane (Table 2).

The four cultivars showed variations in both number of breaks and length per cane, depending on their relative growth habits (Table 2). For instance, 'Show Biz' had many short canes, whereas 'Tropicana' had fewer, longer canes and produced the greatest cane length overall.

All rose plants held initially for 4 weeks at $3 \mathrm{C}$ survived the first growing season in the field. Overall, $88 \%$ of all plants held at $23 \mathrm{C}$ survived through the first growing season into fall. Of the four cultivars, 'Femme' was the most sensitive to simulated marketing at $23 \mathrm{C}$, with only $72 \%$ survival through the summer. In contrast, 'Tropicana', 'Hotel Hershey', and 'Show Biz' had 94\%, 89\%, and $94 \%$ survival, respectively, following holding at $23 \mathrm{C}$. 
Only $38 \%$ of untreated rose bushes initially held at $23 \mathrm{C}$ initiated budbreak the second season after planting. In contrast, only one plant ('Femme') out of 24 that were initially waxed and held at $3 \mathrm{C}$ before planting died during the first year.

To our knowledge, no previous study has investigated the effect of elevated simulated marketing temperatures on subsequent field performance, despite the fact that millions of roses are mass-marketed under these conditions annually. The results of this study indicate that 4 weeks at $23 \mathrm{C}$ can have an unacceptable impact on the subsequent performance of packaged rose plants; Overall, when compared to plants held at $23 \mathrm{C}$, plants held at $3 \mathrm{C}$ had much higher moisture content of canes at planting, produced nearly twice as many budbreaks, twice as many flowers, and twice as much total cane growth. The negative effects of $23 \mathrm{C}$ were noted for all treatment combinations, independent of the four rose cultivars tested or moisture barriers used to protect canes. It should be noted that these experiments were initiated on 4 May and it is possible that the storage temperature effect may not be as severe in early spring. However, late marketing of roses is common in the northern United States, where the last frost-free date is in early to late May.

\section{Literature Cited}

Janne, E.E. and L.C. Chadwick. 1951. Influence of storage and pruning practices on the growth and flower production of outdoor roses. Proc. Amer. Soc. Hort. Sci. 57:387-392.

Mahlstede, J.P. and W.E. Fletcher. 1960. Storage of nursery stock. Amer. Assn. Nurserymen, Washington, D.C.

Toy, S.J. 1959. Effect of paraffin waxes on growth and physiology of rose plants. PhD Diss., Iowa State College, Ames.

Toy, S.J. and J.P. Mahlstede. 1959. Responses of rose plants to cane coating with melted paraffin wax. Iowa State College J. Sci. 33(4):475488.

Yerkes, G.E. and F.E. Gardner. 1934. Dormant rose plants as affected by temperature and moisture while in storage. Proc. Amer. Soc. Hort. Sci. 32:347-350.

\section{Relationship of Fruit Morphology and Weight to Fruit Strength in 'Meeker' Red Raspberry}

\section{JoAnn Robbins ${ }^{1}$ and Patrick P. Moore ${ }^{2}$ \\ Washington State University Puyallup Research and Extension Center, Puyallup, WA 98371}

Additional index words. compression, firmness, Rubus idaeus, fruit quality, path analysis

\begin{abstract}
Fruit weight and morphological characteristics of 'Meeker' red raspberry (Rubus idaeus L.) fruit, including drupelets (height, diameter, number), receptacle cavities (depth, diameter), and pits (individual weight) were measured five times in 1988. Fruit strength, as measured by compression, was recorded. The relationship of fro-it weight to fruit strength had linear and quadratic components. Fruit weight was correlated with fruit strength, drupelet height and number, receptacle cavity depth and diameter, and individual pit weight. Besides fruit weight, fruit strength was correlated with drupelet diameter and number, receptacle cavity depth, and individual pit weight. Drupelet number, receptacle cavity depth, and individual pit weight provided the largest component contribution to fruit strength, as determined by path analysis.
\end{abstract}

Our efforts to develop a red raspberry culfruit morphological characteristics contributing to fruit strength. A previous study using 10 genotypes and path analysis showed that drupelet height and number, receptacle cavity depth and diameter, and individual pit weight were the major components contributing to fruit compression strength (force required to close the fruit opening) (Robbins and Sjulin, 1989). Of these five components,

Received for pubication 2 June 1989. H/LA Paper no. 89-14. Washington State Univ., College of Agriculture and Home Economics, Pullman, Wash. Project no. 0640. Partially supported by a grant from the Washington Red Raspberry Commission. The cost of publishing this paper was defrayed in part by the payment of page charges. Under postal regulations, this paper therefore must be hereby marked advertisement solely to indicate this fact. ${ }^{1}$ Horticulture Research Specialist.

${ }^{2}$ Assistant Horticulturist. tivar with firmer fruit have focused on the only individual pit weight influenced fruit compression strength directly. The other four components increased fruit weight, and heavier fruit were stronger.

The purpose of the current research was to study the relationships among fruit strength, fruit weight, and six other morphological characteristics within a single genotype.

Five harvests were made in 1988 (5, 10, 15,19 , and 25 July) from 'Meeker' red raspberry plants growing in a four-hill plot at Washington State Univ. Puyallup Research and Extension Center, Puyallup. Thirty fruit at the red-ripe stage (Sjulin and Robbins, 1987) were carefully harvested on each date, individually placed in compartments of plastic foam egg cartons, and transported to the laboratory for evaluation. The fruit were chosen with an effort to achieve a continuum of fruit weights, with as wide a range as possible, at each harvest date.

Individual fruits were weighed to within $0.001 \mathrm{~g}$. All measurements were made to 0.1 $\mathrm{mm}$ with calipers. Drupelet height and diameter were measured on three drupelets adjacent to the receptacle cavity opening. Receptacle cavity diameter was measured at the widest point internally across the opening. Fruit strength, as measured by compression (Robbins and Sjulin, 1986), was recorded. Receptacle cavity depth was measured by splitting the fruit longitudinally and measuring the internal surface from the edge of the opening to the tip of the fruit. Pits were extracted by washing and abrading fruit on a fine screen to remove all fleshy material. After air-drying at room temperature for
Table 1. Mean, standard deviation, coefficient of variation, and range of morphological measurements for 'Meeker' red raspberry. (1988).2

\begin{tabular}{lcrr}
\hline \hline $\begin{array}{l}\text { Morphological } \\
\text { characteristic }\end{array}$ & Mean $\pm \mathrm{SD}$ & $\mathrm{CV}$ & Range \\
\hline $\begin{array}{l}\text { Fruit } \\
\text { Strength (Newton) }\end{array}$ & $1.58 \pm 0.39$ & 0.24 & $0.54-2.50$ \\
Wt (g) & $3.00 \pm 0.84$ & 0.28 & $1.52-5.20$ \\
Drupelet & & & $0.31-0.54$ \\
$\quad$ Ht (cm) & $0.44 \pm 0.04$ & 0.09 & $0.20-0.50$ \\
$\quad$ Diam (cm) & $0.32 \pm 0.04$ & 0.13 & $40-126$ \\
No, & $86 \pm 17$ & 0.20 & $0.62-1.54$ \\
Reccptacle cavity & $1.11 \pm 0.20$ & 0.18 & $0.53-1.10$ \\
$\quad$ Depth (cm) & $0.81 \pm 0.11$ & 0.14 & $1.09-2.26$ \\
$\quad$ Diam (cm) & $1.54 \pm 0.21$ & 0.13 & \\
Pit wt & & & \\
Individual (mg) & & & \\
\hline
\end{tabular}

${ }^{2}$ Data over five harvests. 